working as house officers on two surgical firms (box).

Dr Dowling suggests that front line medical services should not be provided by the most junior member of the team working without adequate supervision. She points out that in specialties where the quality of the front line services is a matter of life and death-such as intensive care medicine or accident and emergency work - they are not provided by preregistration staff. But she challenges the assumption that services like postoperative pain control or the provision of medical cover to surgical patients should be seen as less important. She believes that if patients and the purchasers who obtain medical care for them began to demand a better quality of front line service, then hospital managers would very quickly do something to improve the tasks undertaken by and supervision given to preregistration house officers.

\section{Implementing change}

One of the great problems in achieving any change in the preregistration experience is that no one seems to have the power and the will to do much about it. Although the GMC issues recommendations about what the year should provide, it does not have any means of enforcing these. The legal responsibility for the house officer year rests with the universities, which have shown few signs of willingness to rock the existing boat. (One notable exception is the University of London, which recently issued guidelines on what was acceptable in a house officer's post and warned that jobs failing to come up to standard would not be recognised. ${ }^{12}$ )

The people with most interest in changing things are the house officers themselves, but individually they are in a very weak position because they all depend on references from their consultants for registration and career progression. Collectively, however, they have considerable power. Recently the junior staff at Southmead Hospital in Bristol found themselves in bitter dispute with the hospital management over the terms and conditions of their employment. ${ }^{13}$ By chance there were several mature graduates at the hospital, including one who was about to emigrate. These doctors, unlike so many preregistration house officers, were not prepared to be walked over, and a campaign of industrial action-including the threat that future students might boycott the jobs at Southmead-led quickly to remedial action.

Dr Dowling believes that part of the reason why house officers are often so impotent in hospital politics is that they are essentially migrant labour-rarely in one place for more than six months. Managers do not really see them as part of the assets of the unit. She believes that junior doctors could be empowered by longer contracts and proposes that house jobs should be arranged in one year (or even 18 month) blocks within single or closely linked units, so that the doctors felt and were recognised as an important part of the service provided. A scheme like this is now planned for Southmead Hospital.

\section{Empowering the house officer}

The first step in empowering house officers so that change can happen is to ensure that they know what they are entitled to expect from the job. Few house officers have any idea of the contents of the GMC's recommendations on general clinical experience. The GMC should ensure that all final year medical students understand what they can reasonably expect. Ideally there should be a central record of all approved house jobs, detailing the extent to which they meet the recommendations. Such a "good house jobs guide" is proposed in one recent report ${ }^{11}$ and could be produced

\section{Surgical nurse practitioner}

Lou Jacobs has been a nurse for 17 years and has over 12 years' experience in intensive care units. She has been working as a nurse practitioner on a general surgical firm at the Taunton and Somerset NHS Trust since August. In previous years her job has been filled by a preregistration house officer.

Her duties differ from a preregistration house officer's only in line with the legal restrictions on nursing staff. She is not allowed to make diagnoses, initiate drug treatment, or certify death. She clerks patients, organises and attends ward rounds, requests investigations, draws up theatre lists, liaises with anaesthetic and nursing staff and general practitioners, helps in theatre, and does all of the other tasks undertaken by the medical house officers on the other firms at the hospital.

Ms Jacobs finds the job stimulating and admits to being surprised by how hard house officers are expected to work. She suspects that she may get rather more exposure to outpatient clinics and theatre sessions than her medical colleagues because they get bogged down on the wards with tasks that she is not allowed to do. She regards these sessions away from the routine work as some of the most interesting aspects of the job and does not think that the mundane elements of a house officer's post could be "dumped" on another person without some such perks to "relieve the boredom."

by the GMC or the BMA. House officers also need to know what to do if their job falls far short of the recommended standards. It is unreasonable to expect them to tackle problems through their consultants, although if they had independent supervisors this might be possible.

A better way might be for house officers to take collective action through their trade union representatives, and the BMA should take the lead in providing this service. Managers need to appreciate that house officers are a vital part of the service they provide and an asset that should be protected. Attaching doctors to single hospitals for both of their house jobs might be one way of making them a more obvious part of the system.

1 Allen I. Doctors and their careers. London: Policy Studies Institute, 1988

2 British Medical Association. Stress and the medical profession. London: BMA, 1992.

3 Firth-Cozens J. Emotional distress in junior house officers. BMf 1987;295: 533-6.

4 Firth-Cozens J. Stress in medical undergraduates and house officers. Br $\mathcal{J}$ Hosp Med 1989;41:161-4.

5 Rees G. Improving preregistration training. $B M \mathcal{F}$ 1992;304:98

6 Leslie PJ, Williams JA, McKenna C, Smith G, Heading RC. Hours, volume, and type of work of preregistration house officers. BMf 1990;300:1038-41.

7 General Medical Council. Recommendations on general clinical training. London: GMC, 1992.

8 Wilson DH. Education and training of preregistration house officers: the consultants' viewpoint. $B M F$ 1993;306:194-6.

9 Richards P. Educational improvement of the preregistration period in general clinical training. $B M \mathcal{F}^{1992 ; 304: 625-7 .}$

10 Bahrami J. Improving preregistration training. $B M F$ 1992;304:981.

11 Dowling S, Barrett S. Doctors in the making. The experience of the preregistration year. Bristol: School for Advanced Urban Studies, 1992.

12 Richards P on behalf of Council of Deans of United Kingdom Medical Schools and Faculties. Educational improvement of the preregistration period of and Faculties. Educational improvement of
general clinical training. BMF 1992;304:625-7.

13 Fleming C. Staffing dispute in Bristol trust hospital. BMY 1992;305:210.

\section{Correction}

From FPC to FHSA to ... health commission?

A printer's error in this article by June Huntington (2 January, pp 33-6) resulted in the photographs of the practice premises being transposed ( $p 35$ ). As published, the bottom picture shows the existing premises and the top picture shows the additional and independent premises, which was in fact built by the local authority at the request of one of the partners and for which the family practitioner committee/family health services authority has allowed a notional rent. 